\title{
Modelling the Evaporation Rate in an Impingement Jet Dryer with Multiple Nozzles
}

\author{
Anna-Lena Ljung, ${ }^{1}$ L. Robin Andersson, ${ }^{1}$ Anders G. Andersson, ${ }^{1}$ T. Staffan Lundström, \\ and Mats Eriksson ${ }^{2}$ \\ ${ }^{1}$ Division of Fluid and Experimental Mechanics, Department of Engineering Science and Mathematics, Luleå University of Technology, \\ 97187 Luleå, Sweden \\ ${ }^{2}$ Relitor Engineering AB, Företagsvägen 9, 95433 Gammelstad, Sweden
}

Correspondence should be addressed to Anna-Lena Ljung; anna-lena.ljung@ltu.se

Received 22 December 2016; Accepted 5 February 2017; Published 2 March 2017

Academic Editor: Sreepriya Vedantam

Copyright (C) 2017 Anna-Lena Ljung et al. This is an open access article distributed under the Creative Commons Attribution License, which permits unrestricted use, distribution, and reproduction in any medium, provided the original work is properly cited.

\begin{abstract}
Impinging jets are often used in industry to dry, cool, or heat items. In this work, a two-dimensional Computational Fluid Dynamics model is created to model an impingement jet dryer with a total of 9 pairs of nozzles that dries sheets of metal. Different methods to model the evaporation rate are studied, as well as the influence of recirculating the outlet air. For the studied conditions, the simulations show that the difference in evaporation rate between single- and two-component treatment of moist air is only around 5\%, hence indicating that drying can be predicted with a simplified model where vapor is included as a nonreacting scalar. Furthermore, the humidity of the inlet air, as determined from the degree of recirculating outlet air, has a strong effect on the water evaporation rate. Results show that the metal sheet is dry at the exit if $85 \%$ of the air is recirculated, while approximately only $60 \%$ of the water has evaporated at a recirculation of $92,5 \%$.
\end{abstract}

\section{Introduction}

Impinging jets are frequently used in industry with the purpose of drying, cooling, or heating different artefacts [1]. Impingement drying is especially common for continuous sheets such as paper, textiles, and metals. Metal sheets can, for example, be transported through an impingement jet dryer after painting to evaporate the water from the surface. Energy consumption and environmental issues are naturally important factors in drying processes [2-4] and impingement jet drying is no exception. It is therefore essential to further increase the knowledge of the drying technique to enable a reduction of the energy consumption while still providing a proper drying.

Impingement jet heat transfer is an active area of research and extensive numerical work has been carried out on the heat transfer from single and twin impingement jets (e.g., [5-11]). Prediction of the turbulent fluid flow in a correct manner is, for instance, of absolute importance and in the work of Wang and Mujumdar [6] five low Reynolds number
(Re) turbulence models were examined. Results show that although corrections increased agreement with experimental data, none of the turbulence models manages to predict the local Nusselt number $(\mathrm{Nu})$ over the whole domain in an adequate manner. The more advanced SST-SAS (Shear Stress Transport with Scale Adaptive Simulation) model showed, in its turn, fairly accurate results in a twin-jet impingement study [11].

A review on multiple jet impingement was carried out by Weigand and Spring [12]. Olsson et al. [13] simulated flow around two and three jets with $k-\omega$ SST turbulence model and results display that both distance and opening between the jets are important for the heat transfer rates in the stagnation zone. Elliptical and rectangular impingement jets were examined both experimentally and numerically by Caliskan et al. [14], yielding an enhanced heat transfer coefficients for elliptical jets. The detailed study, furthermore, discloses the formation of upward flow between two adjacent jets. Large Eddy Simulations (LES) of multiple circular impingement jets were carried out by Draksler et al. [15], resulting in 


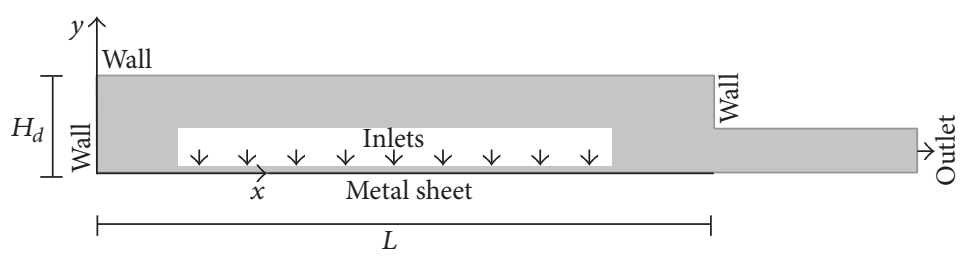

FIGURE 1: Schematic picture of the computational domain that comprises nine inlets and one outlet; that is, symmetry is applied below the metal sheet. It is possible for the air to flow between the inlets, but the actual geometry of the pipes and nozzles supplying the inlet air is not displayed here due to confidentiality.

accurate predictions of main flow features. Moreover the study indicates that two-equation turbulence models can, except in the near-wall region where adjacent jets interact, provide a good approximation of the flow. A good agreement between LES and experiments is also found in the study by Kharoua et al. [16].

Evidently there is comprehensive research on impingement jet heat transfer but the inclusion of moisture in the numerical models has to the authors' knowledge been given less attention. De Bonis and Ruocco [17] numerically analyzed local heat and mass transfer in food slabs due to air jet impingement. Jet impingement over a moist protrusion was studied based on conjugate heat and mass exchange, enabling studies of jet height, protrusion size, and flow rate by De Bonis and Ruocco [18]. A single wet particle in a two-dimensional pulsed opposing jet contractor (POJC) was analyzed by Yahyaee et al. [19], showing an increased drying performance with increased pulsation amplitude and increased jet Re. Moisture was furthermore included in the work by Bai et al. [20], where effects of a moving plate were considered. Constant boundary conditions were adopted at the surface of the moving plate, and simulations yielded a detailed distribution of the velocity, temperature, and moisture.

From a modelling point of view, it is of interest to further examine how to include effects of moisture distribution and evaporation. There are several ways to determine the evaporation rate in forced convective flows such as impingement jets. The moisture field may be simulated by the use of separate components of vapor and air or as a scalar distribution where the influence of vapor on the fluid flow is neglected and hence the computational effort is decreased. Evaporation rate can also be determined from correlations of Nusselt number $(\mathrm{Nu})$ and Sherwood number $(\mathrm{Sh})$ found, for example, in literature or derived from simulations. With the use of analogies between $\mathrm{Nu}$ and $\mathrm{Sh}$ it is furthermore possible to derive a local mass transfer coefficient from the thermal field alone, that is, without including moisture. The use of correlations is common in various drying applications [21, 22]. The drawback of using correlations is that no information is given about the distribution of moisture inside the dryer. Since the listed methods have different pros and cons, it is of interest to compare the validity and applicability.

In the current paper, a study of a metal sheet impingement dryer with multiple nozzles is presented with aid of CFD. The SST turbulence model is adopted and the geometry is based on a dryer with 9 pairs of nozzles. Special attention is put on modelling strategies for the evaporation rate and vapor content as well as the influence of recirculating air.

\section{Modelling}

The metal sheet dryer selected for this study is shortly outlined below followed by a description of the numerical model and the governing equations.

2.1. The Dryer. Impingement jet dryers can be designed in numerous ways regarding, for instance, nozzles, capacities of the fan, capacity of the heat exchanger, and space limits for the setup. The nozzles in the dryer chosen for this study are placed in 9 pairs, that is, 9 above and 9 below the metal sheet. The humid air exiting the dryer is funneled back to the nozzles via a fan and a heat exchanger in order to increase the energy efficiency of the dryer. To overcome problems of high humidity in the inlet air, an outtake before the heat exchanger bleeds about $5-10 \%$ of the total circulated air. The heat exchanger then reheats the mixture of circulated and fresh air to the desired inlet temperature. The bleeding of air will, however, lead to a loss in efficiency since new air must be heated, and it is therefore of interest to keep the outtake of moist air at a minimum.

Rectangular nozzle openings are used to direct air jets onto the sheet. The dryer has a dimensionless nozzle-toplate distance, $Z / B$, of around 13 , while the aspect ratio of the nozzles is around 300. The rectangular shape and relatively high aspect ratio of the nozzles enable the use of a two-dimensional numerical model; see Figure 1. The dryer is furthermore symmetrical above and below the metal sheet and only the top half of the dryer is therefore considered; see Figure 1 where the external walls and flow directions of the computational domain is presented. Nine nozzles are included to investigate the interaction between the impingement jets. A list of input parameters is displayed in Table 1.

The following assumptions are introduced:

(i) Gravity is not included.

(ii) The motion of the sheet is neglected. As suggested [23], surface motion may be neglected if the surface linear velocity is less than $20 \%$ of the jet velocity at impact. 
(iii) The sheet is assumed to have a constant temperature throughout the drying process; hence effect of plate thickness is not accounted for. The validity of this assumption is discussed in the Results and Discussion.

(iv) Leakage of air at the entrance and exit of the sheet is not considered in the model.

(v) A plug velocity profile is used at the inlets. The nozzle shape is, consequently, represented with a simple sharped edged slot [24].

(vi) Humidity in the fresh air is not included.

2.2. Theory. The following Reynolds averaged Navier-Stokes equations govern the turbulent flow of air inside the dryer:

$$
\begin{aligned}
& \frac{\partial \rho}{\partial t}+\frac{\partial \rho U_{j}}{\partial x_{j}}=0 \\
& \frac{\partial \rho U_{i}}{\partial t}+\frac{\partial\left(\rho U_{i} U_{j}\right)}{\partial x_{j}}=-\frac{\partial p}{\partial x_{i}}+\frac{\partial}{\partial x_{j}}\left(\tau_{i j}-\rho \overline{u_{i} u_{j}}\right), \\
& \frac{\partial\left(\rho H_{\mathrm{tot}}\right)}{\partial t}-\frac{\partial p}{\partial t}+\frac{\partial}{\partial x_{j}}\left(\rho U_{j} H_{\mathrm{tot}}\right) \\
& \quad=\frac{\partial}{\partial x_{j}}\left(\lambda \frac{\partial T}{\partial x_{j}}-\rho \overline{u_{j} H}\right)+\frac{\partial}{\partial x_{j}}\left[U_{i}\left(\tau_{i j}-\rho \overline{u_{i} u_{j}}\right)\right] .
\end{aligned}
$$

Turbulence models provide closure of the Reynolds average equations and, for eddy viscosity turbulence models, the assumptions of eddy viscosity and eddy diffusivity introduce the expressions

$$
\begin{aligned}
\rho \overline{u_{i} u_{j}} & =\mu_{t}\left(\frac{\partial U_{i}}{\partial x_{j}}+\frac{\partial U_{j}}{\partial x_{i}}\right)-\frac{2}{3} \delta_{i j}\left(\rho k+\mu_{t} \frac{\partial U_{k}}{\partial x_{k}}\right), \\
\rho \overline{u_{i} \phi} & =\Gamma_{t} \frac{\partial \Phi}{\partial x_{i}}
\end{aligned}
$$

where $\mu_{t}$ is the turbulent viscosity and $\Gamma_{t}$ is the turbulent diffusivity. The constitutive equations for density and enthalpy of air are based on the ideal gas equations of state; that is,

$$
\begin{aligned}
\rho & =\frac{w p_{\mathrm{abs}}}{R T}, \\
d H & =c_{p} d T .
\end{aligned}
$$

The material variables in (1) will represent dry air or a mixture of air and water vapor depending on the case studied. The material variables $c_{p}, \mu$, and $\lambda$ for the mixture of air and water vapor are derived as a mass fraction weighted average following the relationship here exemplified for $\mu$ as

$$
\mu=\mu_{a} \varphi_{a}+\mu_{v} \varphi_{v}
$$

while air is set as the constraint component with its mass fraction calculated from

$$
\sum_{i} \varphi_{i}=1
$$

TABle 1: Parameters of the reference dryer.

\begin{tabular}{lc}
\hline Parameter & Value \\
\hline Inlet temperature & $418.15 \mathrm{~K}$ \\
Mass flow & $13.38 \mathrm{~kg} / \mathrm{s}$ \\
Sheet temperature & $313.15 \mathrm{~K}$ \\
Water film volume & $5 \cdot 10^{-6} \mathrm{~m}^{3} / \mathrm{m}^{2}$ \\
Number of nozzles & 18 \\
\hline
\end{tabular}

Two methods to determine the flow of water vapor in the dryer are examined: moisture included as a scalar in a singlecomponent flow and inclusion of moisture through twocomponent flow of air and vapor.

2.2.1. Two-Component Treatment of Moist Air. If vapor is included in the air composition, a mass fraction transport equation is solved in addition to (1) to calculate the transport of vapor in air according to

$$
\frac{\partial \rho \varphi_{v}}{\partial t}+\frac{\partial}{\partial x_{j}}\left(\rho U_{j} \varphi_{v}\right)=\frac{\partial}{\partial x_{j}}\left(\Gamma \frac{\partial \varphi_{v}}{\partial x_{j}}-\rho \overline{u_{j} \phi}\right) .
$$

2.2.2. Single-Component Treatment of Moist Air. The conserved quantity per unit mass, $\varphi=\Phi / \rho$, modelled as a scalar will depend solely on the existing fluid flow and diffusion and an increase in vapor mass density will not influence the flow. The variable is determined from a transport equation; see (6).

2.3. Boundary Conditions. No slip boundary conditions are applied at all walls and inlet temperature and velocity are set according to Table 1 . The boundary condition at the metal sheet is based on the assumption that the air is fully saturated with vapor at the surface where the liquid film exists. The saturated mass density of vapor is derived from the ideal gas law as

$$
\rho_{v, \mathrm{sat}}=\frac{w p_{v, \mathrm{sat}}}{R T}
$$

The saturated pressure, $p_{v \text {,sat }}$, is the vapor pressure corresponding to saturation at temperature $T$ as derived from Antoine's equation [25] according to

$$
\ln \left(\frac{p_{\text {sat }}}{1.333 \cdot 10^{2}}\right)=A-\frac{B}{C+T}
$$

with $A=18.3036, B=3816.44$, and $C=-46.13$. The evaporation rate at the surface of the metal sheet is then obtained from Fick's law as

$$
\dot{m}=-D_{\mathrm{av}} \rho \nabla \varphi_{v}
$$

The expression is used to calculate evaporation rate both for the variable composition mixture and for the nonreacting scalar. For simulations with vapor treated as a scalar, vapor is included through a boundary condition at the sheet surface equal to (7). For the variable composition mixture, however, the vapor density at the sheet surface cannot be set directly 
according to (7), and the saturation at the surface is instead controlled through a step function. A mass flux at the sheet surface is then applied through a source term and a step function controls the saturation at the surface. For convergence the mass density of vapor is kept in an interval of maximum $1.0 \%$ from its theoretical value.

The heat transfer coefficient, $h$, at the sheet surface is derived from

$$
h=\frac{q_{n}^{\prime \prime}}{\left(T_{s}-T_{\infty}\right)}
$$

where $q_{n}^{\prime \prime}$ is the local heat flux determined from Fourier's law as

$$
q_{n}^{\prime \prime}=-\lambda \frac{\partial T}{\partial n}
$$

If the flow is mainly driven by temperature difference and $h$ is known, the mass transfer coefficient $h_{m}$ may be obtained from the heat and mass transfer analogy according to

$$
\frac{h}{h_{m}}=\frac{k}{D_{\mathrm{av}} L e^{1 / 3}}
$$

enabling computation of $h_{m}$ without including moisture in the simulations. The mass flux may then be determined from the difference in concentration between the saturated vapor at the surface and the surrounding relative saturation as [26]

$$
\dot{m}_{l}=h_{m} \frac{w_{l}}{R}\left(\frac{p_{v, \text { sat }}\left(T_{s}\right)}{T_{s}}-\frac{p_{v, \text { sat }}\left(T_{\infty}\right) \mathrm{RS}}{T_{\infty}}\right) .
$$

The gas properties in (14) are evaluated at the arithmetic mean temperature of the thermal boundary layer [26]. The relative saturation, RS, is determined from

$$
\mathrm{RS}=\frac{p_{v}}{p_{v, \text { sat }}} .
$$

Important to note is, however, that calculation of evaporation rate based on the heat and mass transfer analogy does not provide any knowledge about the distribution of vapor inside the dryer; that is, inlet relative saturation due to recirculating air cannot be determined using this method.

Investigations of the influence of recirculating air are carried out using single-component treatment of air, with vapor modelled as a scalar. The moisture content in the inlet air is derived from the average outlet moisture content with a correction factor to account for the outtake of moist air.

2.4. Numerical Method. The simulations are carried out with the CFD software ANSYS CFX 15 that utilises a hybrid Finite Volume/Finite Element solver [27]. The simulations are run in steady state mode except for when vapor is included as a two-component mixture. A steady state simulation of the temperature field is then used for initiation and the simulation is run until a steady state solution is reached. Specific initial conditions are otherwise disregarded (i.e., velocities and mass fractions in the computational domain are set to zero for initiation). All simulations are run with convergence criteria of Root Mean Square (RMS) residual $<10^{-7}$. The flow inside the dryer is turbulent and the SST turbulence model is applied. The SST model is regarded to have a superior near-wall treatment when compared with the standard $k-\varepsilon$ model since it uses a $k-\omega$ formulation close to the wall and a $k-\varepsilon$ formulation in the free-stream; however it is less computational demanding when compared to DES (Detached Eddy Simulation) and LES based turbulence models.

The geometry is discretized to structured hexagonal grids, one-element thick, in the meshing software ANSYS ICEM CFD 14. The grids have O-shaped blocks around the pipes with local refinements at the nozzle inlets to better resolve the jets. The grids are also refined near the plate and the bounding walls of the dryer in order to benefit from the nearwall treatment of the SST model. A Y $+<2$ is obtained for the plate.

\section{Results and Discussion}

A mesh study is first carried out followed by a validation of $h$. Three different methods to calculate the evaporation rate are then compared and finally the influence of the recirculating air is addressed.

3.1. Mesh Study. Three grids are created with $77 \mathrm{k}, 123 \mathrm{k}$, and $174 \mathrm{k}$ nodes, respectively, and simulated without the effect of water vapor. With initial conditions according to Table 1 , the area averaged heat transfer along the plate for the three grids shows good mesh convergence; see Figure 2. It should be noted that the interactions of the jets are sensitive to both numerical grids and the initial values of the simulation. This is most likely due to geometrical aspects and the $2 \mathrm{D}$ approximation in addition to the large inlet velocity and short distance to the plate. The grid sensitiveness is exemplified in Figure 3 where adjacent jets interact differently for the same positions on the different grids. The two finest meshes correlate best with regard to location and magnitude of the maximum transfer coefficients at the stagnation points, although local differences are observed. Further refinement of the mesh requires time-resolved simulations and, consequently, since the difference is only marginally reflected in values of the area averaged heat transfer (see Figure 2), the finest grid is used in all further simulations. The use of advanced turbulence models and a transient study are recommended if further detail is needed from the simulations. Although care should be taken in the conclusions regarding fluid flow distribution near the plate, the level of detail is considered sufficient for the present study.

3.2. Validation of $h$. To validate the fluid flow and turbulence model in the dryer, the heat transfer coefficient in the impingement zone is compared to experimental data from Hardisty and Can [24]. In the present simulations the air is injected into the dryer as a plug velocity profile which is regarded to be representative of a sharped edge slot. The effective nozzle width, $B^{\prime}$, can be derived from $B^{\prime}=C_{d} B$, where $B$ is the real nozzle width and $C_{d}$ is the discharge coefficient. 


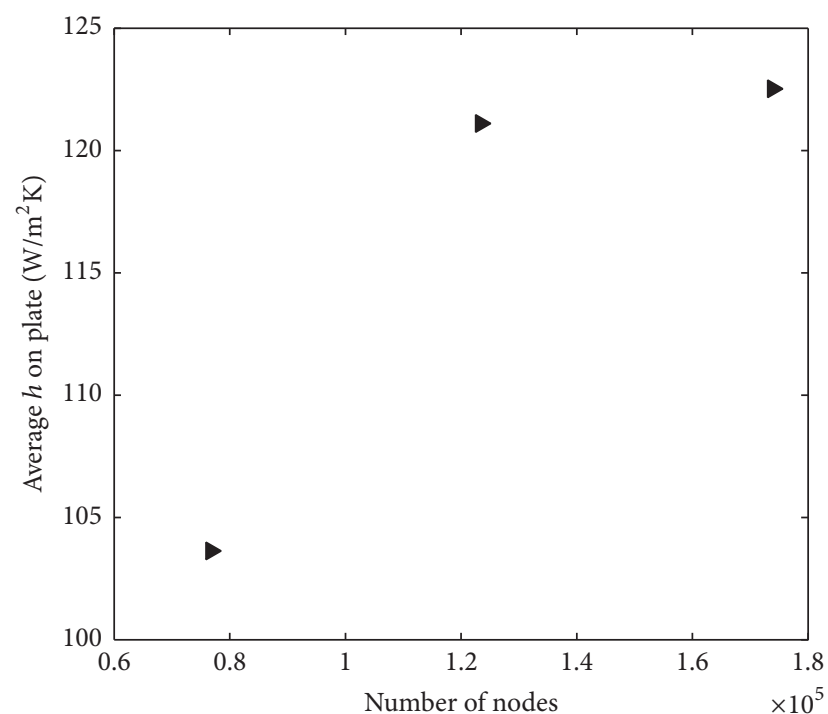

FIGURE 2: Grid convergence study.

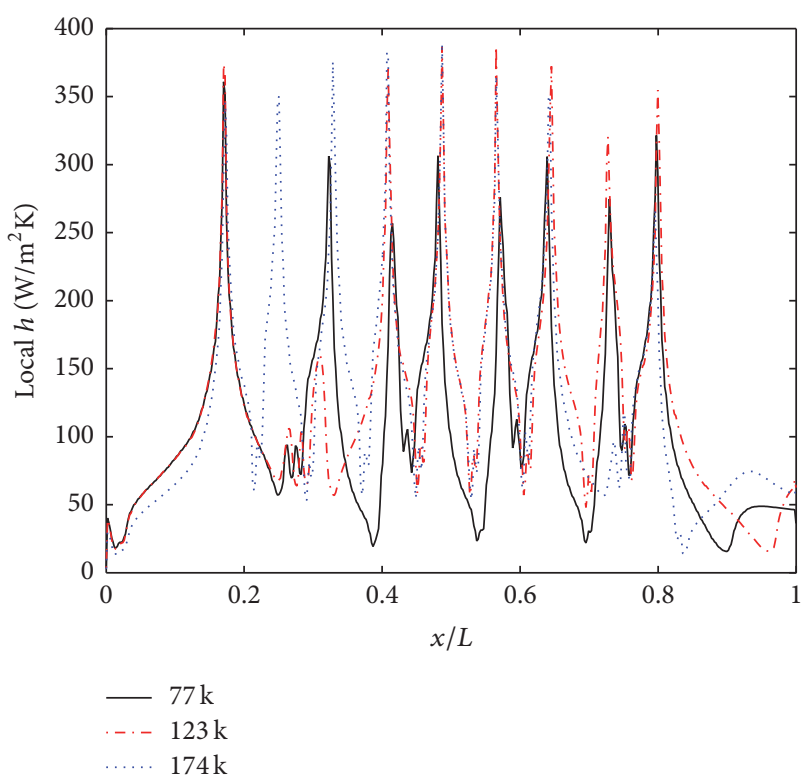

FIGURE 3: Local $h$ as a function of normalized distance $x / L$ from the sheet entrance region for three resolutions of the grid.

With an approximation of $C_{d}=0.68$ [24], the dimensionless nozzle-to-plate distance, $Z / B^{\prime}$, is reapproximated to $Z / B^{\prime} \approx$ 20 in the dryer. Mimicking the experimental setup in [24] with a velocity of $U_{\text {in }}=52.5 \mathrm{~m} / \mathrm{s}$ at an inlet temperature of $T_{\text {in }}$ $=293.15 \mathrm{~K}$ and a plate surface temperature of $T_{s}=373.15 \mathrm{~K}$, simulations of the dryer show nine clear maximums of the heat transfer coefficient, $h$, along the metal sheet, that is, one maximum for each jet; see Figure 4.

A comparison between the stagnation point heat transfer coefficients, $h_{0}$, from Figure 4 with the value attained from [24] at $Z / B \approx 20$ yields a good agreement even though nine jets are considered in these simulations. A value of $h_{0} \approx 350 \mathrm{~W} / \mathrm{m}^{2} \mathrm{~K}$ is retrieved from [24], to be compared

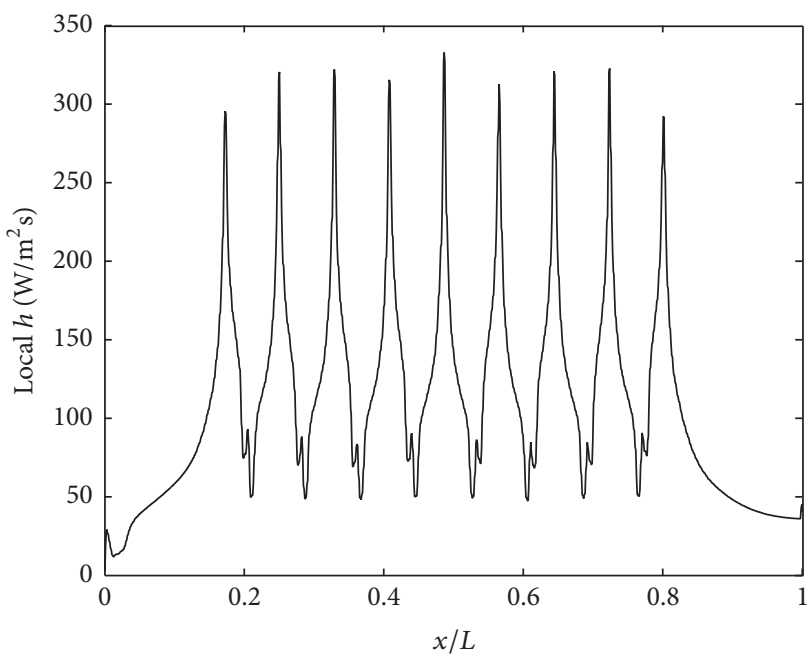

FIGURE 4: Local $h$ at 1000 positions along the sheet as a function of normalized distance $x / L$ from the sheet entrance region.

with an average maximum value of $h_{0}=331 \mathrm{~W} / \mathrm{m}^{2} \mathrm{~K}$ retrieved from simulations considering all jets. The maximum value of $h_{0}$ attained from simulations, $h_{0}=353 \mathrm{~W} / \mathrm{m}^{2} \mathrm{~K}$, is found at the stagnation point of the middle jet being even closer to experimental data.

\subsection{Comparison between Methods to Derive the Evaporation} Rate. Three methods to calculate the evaporation rate are compared for verification of the simulations; vapor treated as a scalar, variable composition mixture of air and vapor, and evaporation rate through the heat and mass transfer analogy (HMTA). The boundary conditions are set according to Table 1 and the simulations are run without recirculating moisture, since results from the HMTA will predict the evaporation rate without further determination of the distribution of moisture inside the dryer. The three methods give similar results as can be seen in Figure 5 and Table 2, where the local and average evaporation rates are displayed, respectively. The largest difference, approx. 20\%, is seen between the heat and mass transfer analogy and vapor included as a scalar, while the difference between the scalar and variable composition mixture is only around 5\%. From Figure 5 it is furthermore apparent that the evaporation rate will follow the heat and mass transfer coefficients with maximal values right below the impingement jets.

The determined evaporation rates can also be used to challenge the assumption of constant sheet temperature. Estimations show that the combination of latent heat needed to evaporate the water and heating from the jets would affect the temperature with only a few degrees during drying if constant temperature through the sheet is assumed.

3.4. Influence of Recirculating Air. Next the influence of recirculating air is studied. Due to the decreased computational effort, the moisture is here modelled as a scalar. Outtake percentages, $\mathrm{OP}$, of $7.5 \%, 10 \%, 12.5 \%, 15 \%$, and $17.5 \%$ are investigated. Firstly the temperature and velocity fields are 
TABLE 2: Area average evaporation rates and relative difference compared to simulations where moisture is included as a two-component mixture of air and vapor.

\begin{tabular}{lcc}
\hline Method & Evaporation rate $\left[\mathrm{kg} / \mathrm{m}^{2} \mathrm{~s}\right]$ & Relative difference $[\%]$ \\
\hline Scalar & 0.00575 & 4,69 \\
Two-component mixture & 0.00605 & \\
Heat and mass transfer analogy & 0.00687 & 13,5 \\
\hline
\end{tabular}

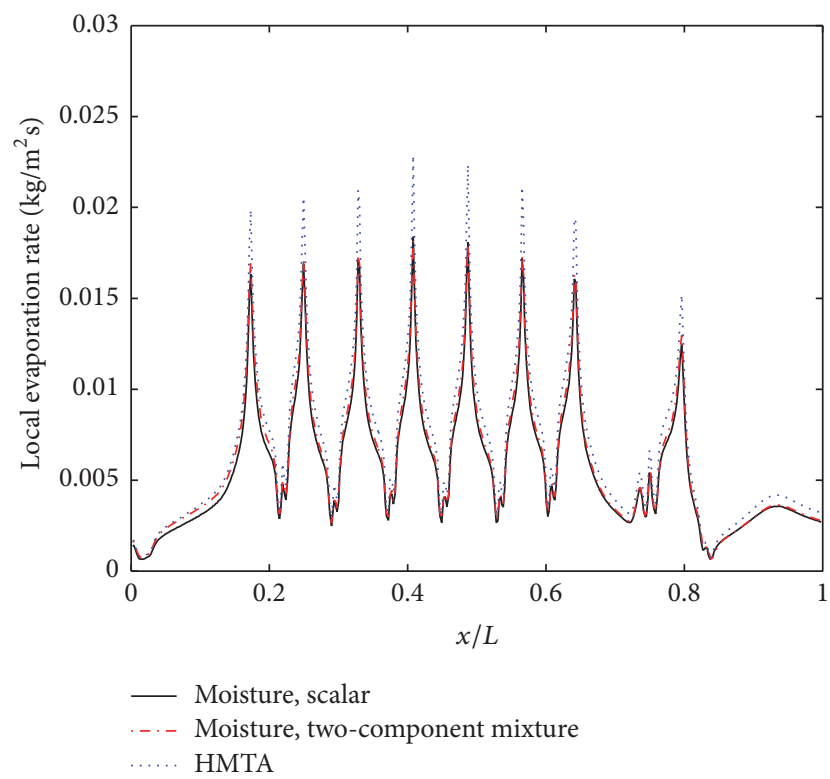

FIGURE 5: Local evaporation rate as a function of normalized distance from sheet entrance.

examined, which are independent of OP. A primary stagnation point under the jet and a secondary stagnation point between the jets are observed; see Figure 6 where the velocity field and vectors are displayed for the jet located in the middle of the row (see Figure 1). A recirculation zone is observed between the primary and secondary stagnation point, and upwash flow is observed above the secondary stagnation point. This is together with the unsymmetrical positions of the secondary stagnation points in correspondence with the findings by Caliskan et al. [14] and Kharoua et al. [16]. For the studied case, the asymmetry could be partly due to the location of the outlet. The corresponding temperature field is displayed in Figure 7, showing the same trends as the velocity field with regard to stagnation points.

Secondly the surface average evaporation rate is investigated assuming a film of water across the whole sheet, that is, initially no regards are taken to whether or not all water is evaporated before the exit. Results show a deceleration of evaporation rate for low OP. Only for OP $=15 \%$ and $17.5 \%$ the sheet is completely dry before the exit, see Figure 8 where results from simulations are compared to the required evaporation rate determined from process values. An OP of $100 \%$ represents dry air at the inlet.

The magnitude of the evaporation rate is observed to increase with OP, that is, reduced relative saturation, while

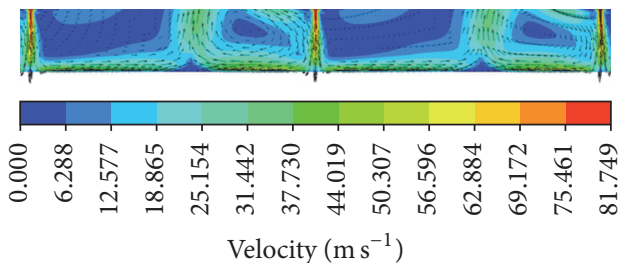

Figure 6: Local velocity below the middle jet. Three jets are displayed in the picture.

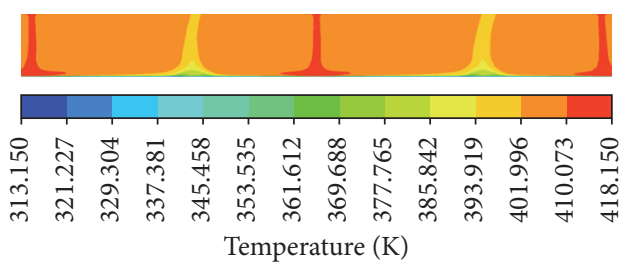

FIgURE 7: Local temperature below the middle jet. Three jets are displayed in the picture.

the locations of the maximum and minimum evaporation rates remains as long as water is present on the sheet, see Figure 9 where the local evaporation rates are displayed for $\mathrm{OP}=10,12.5$ and $15 \%$ at $T_{\text {in }}=418 \mathrm{~K}$. A step function is here introduced to account for the zero evaporation rates at dry areas of the sheet. As seen in Figure 9, the evaporation rate is zero close to the exit of the metal sheet for the outtake of $15 \%$, since the drying is completed before the sheet exits the dryer. The two jets closest to the outlet furthermore show a different behavior than the rest of the jets, possibly due to geometrical considerations.

To further investigate the efficiency of the dryer, the ratio of dried water volume divided by initial water volume is calculated. At an OP of $15 \%$ the metal sheet is totally dry at the exit while at $7.5 \%$ only approx. $60 \%$ of the water has evaporated, see Figure 10.

Recondensation of moist air could impose a possible risk of reducing the dryer efficiency, especially if the saturation is high close to the outlet. To examine the risk of condensation, the relative saturation, RS, is investigated above and below the nozzles. At $\mathrm{OP}=15 \%$, the simulations show that the highest $\mathrm{RS}$ above the plate is attained at the entrance region, see Figure 11 where the local RS inside the dryer is displayed at four normalized heights. Results thus show a low risk of recondensation as the RS is only a few percent, with maximal RS for the positions closest to the plate of around 6\%. The fairly low RS is further confirmed in Figure 12 where the local 


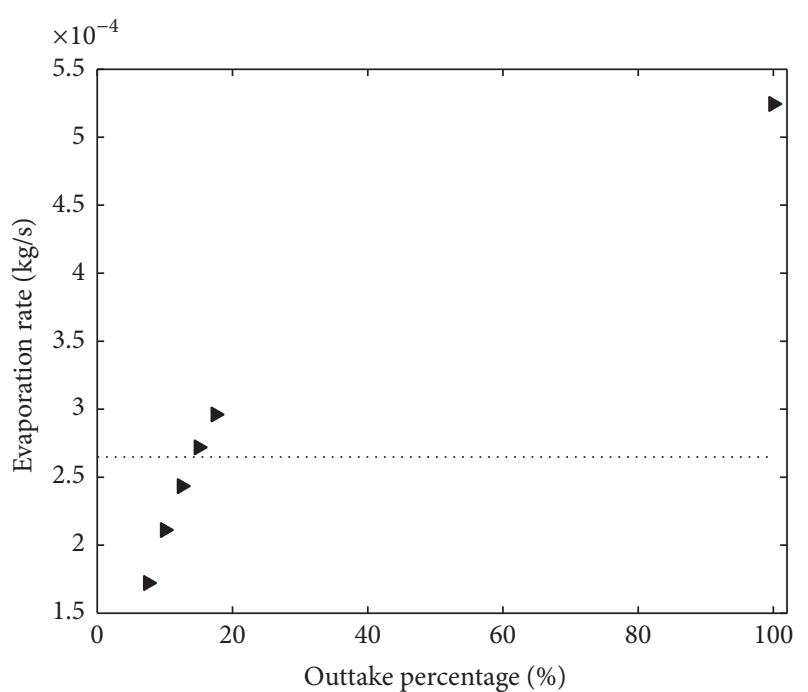

- Simulated

. Required

FIGURE 8: Area average evaporation rate as a function of OP.

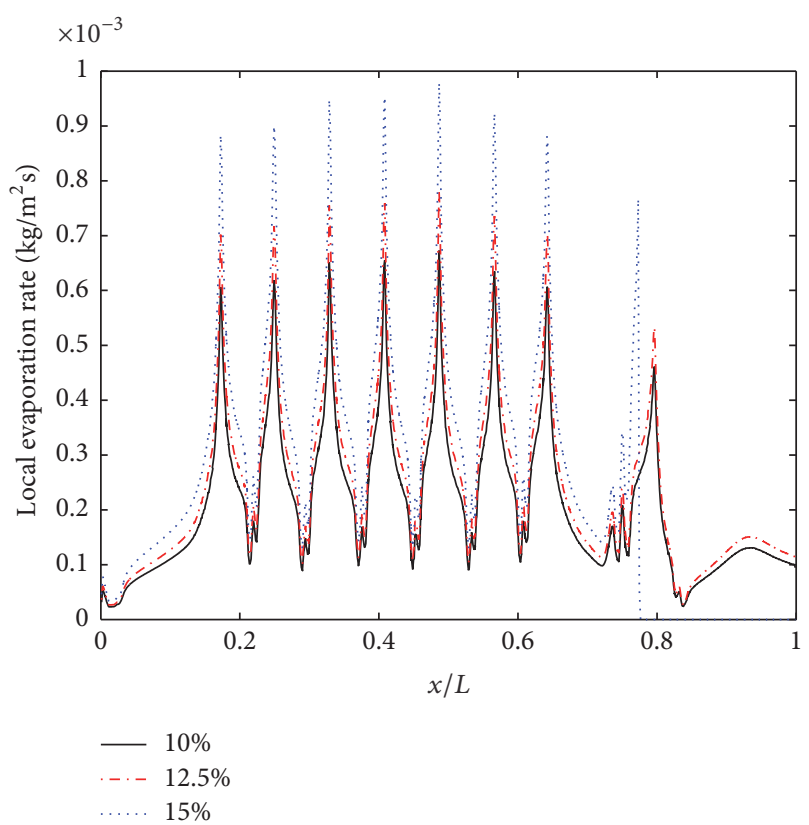

Figure 9: Comparison of local evaporation rates at different outtakes of moist air.

vapor density below the middle jet is displayed for $\mathrm{OP}=15 \%$. The maximum moisture content is attained at the surface of the sheet and distinct areas of increased moisture content in the secondary stagnation points is displayed, see Figure 12.

\section{Conclusions}

This study shows the potential of using CFD as a mean to improve the fluid flow in impingement jet dryers. By treating vapor as a scalar, the evaporation rate can still be predicted

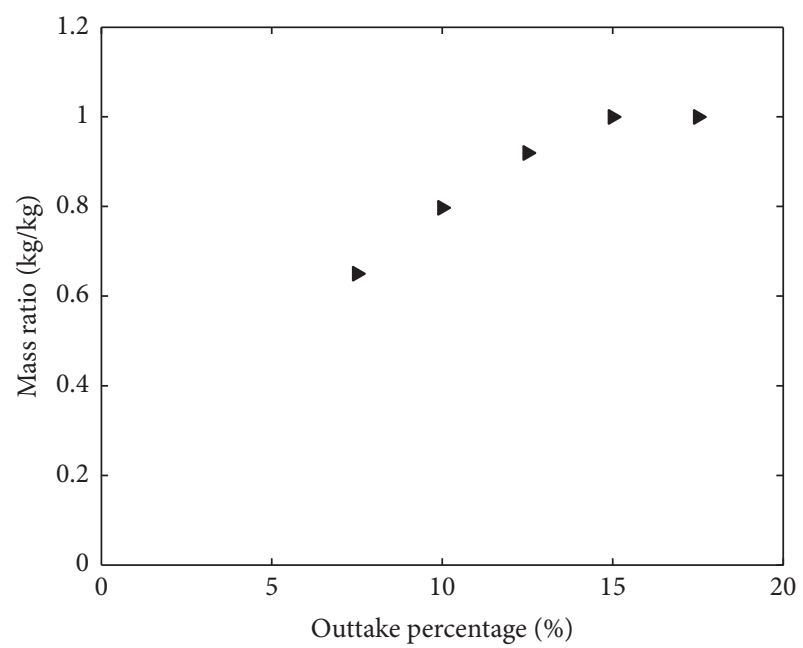

FIGURE 10: Mass ratio of evaporated water as a function of OP.

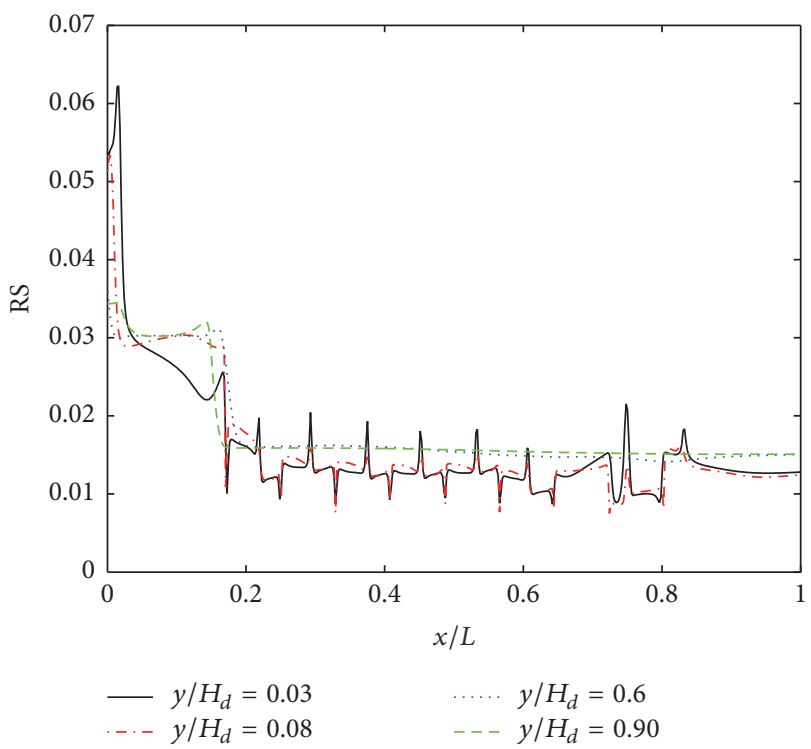

FIGURE 11: RS at normalized heights inside the dryer as a function of normalized distance from the entrance. The sheet is located at $y=0$ (see Figure 1).

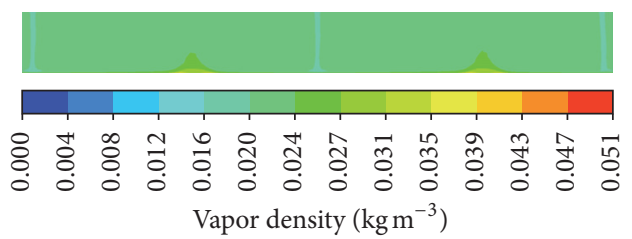

Figure 12: Local density of vapor below the middle jet at $\mathrm{OP}=15 \%$. Three jets are displayed in the picture.

with good accuracy, both compared to results from the heat and mass transfer analogy and with results from a full model where water vapor is included in the composition of the air. A comparison between simulated values of the stagnation point heat transfer coefficient, $h_{0}$ and experimental results from the literature also yields a good agreement. Results furthermore 
show that the evaporation rate in the impingement dryer is highly dependent on the saturation of vapor in the inlet air. The risk of condensation inside the dryer is in its turn low for the studied conditions. Interestingly, the two jets closest to the outlet show a lower impact than the other nozzles indicating that there is a potential of improvement if the fluid flow close to the nozzles is further investigated. Including $3 \mathrm{D}$ effects, transient behavior and more advanced turbulence models will give even more conclusive results.

\section{Nomenclature}

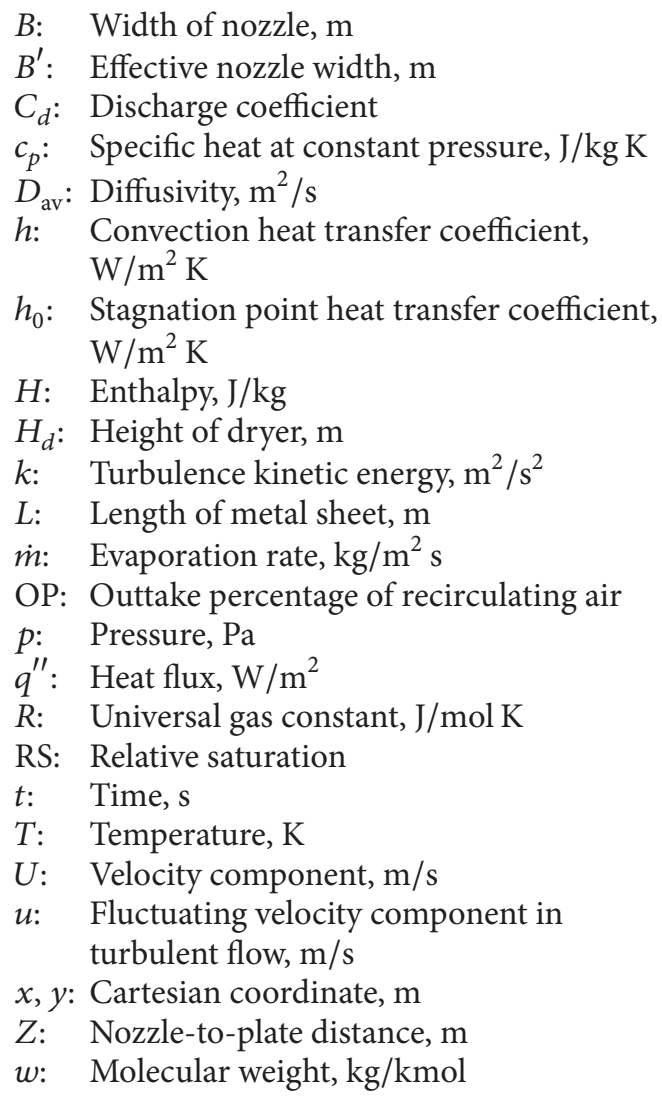

\section{Greek Letters}

$\Gamma:$ Diffusivity, $\mathrm{kg} / \mathrm{m} \mathrm{s}$

$\delta_{i j}$ : Identity matrix

$\lambda$ : Thermal conductivity, $\mathrm{W} / \mathrm{m} \mathrm{K}$

$\mu$ : Dynamic viscosity, $\mathrm{kg} / \mathrm{m} \mathrm{s}$

$\tau_{i j}$ : Shear stress tensor, $\mathrm{kg} / \mathrm{ms}^{2}$

$\rho:$ Density, $\mathrm{kg} / \mathrm{m}^{3}$

$\phi$ : General scalar variable

$\varphi$ : Mass fraction

$\Phi$ : Concentration variable.

\section{Subscripts}

$\begin{array}{ll}a: & \text { Air } \\ \text { abs: } & \text { Absolute } \\ i, j, k: & \text { Tensor index } \\ \text { in: } & \text { Inlet } \\ l: & \text { Liquid }\end{array}$

\author{
$n$ : Surface normal \\ $s$ : Surface \\ sat: Saturated \\ $t$ : Turbulent \\ tot: Total \\ v: Vapor.
}

\section{Competing Interests}

The authors declare that they have no competing interests.

\section{Acknowledgments}

The authors would like to acknowledge Norrbottens Forskningsråd for their financial support.

\section{References}

[1] A. Avci and M. Can, "Analysis of the drying process on unsteady forced convection in thin films of ink," Applied Thermal Engineering, vol. 19, no. 6, pp. 641-657, 1999.

[2] A.-L. Ljung, T. S. Lundström, B. D. Marjavaara, and K. Tano, "Influence of air humidity on drying of individual iron ore pellets," Drying Technology, vol. 29, no. 9, pp. 1101-1111, 2011.

[3] A.-L. Ljung, V. Frishfelds, T. S. Lundström, and B. D. Marjavaara, "Discrete and continuous modeling of heat and mass transport in drying of a bed of iron ore pellets," Drying Technology, vol. 30, no. 7, pp. 760-773, 2012.

[4] A.-L. Ljung, E. M. Lindmark, and T. S. Lundström, "Influence of plate size on the evaporation rate of a heated droplet," Drying Technology, vol. 33, no. 15-16, pp. 1963-1970, 2015.

[5] Z. Q. Lou, A. S. Mujumdar, and C. Yap, "Effects of geometric parameters on confined impinging jet heat transfer," Applied Thermal Engineering, vol. 25, no. 17-18, pp. 2687-2697, 2005.

[6] S. J. Wang and A. S. Mujumdar, "A comparative study of five low Reynolds number $\mathrm{k}-\varepsilon$ models for impingement heat transfer," Applied Thermal Engineering, vol. 25, no. 1, pp. 31-44, 2005.

[7] M. Raisee, A. Noursadeghi, B. Hejazi, S. Khodaparast, and S. Besharati, "Simulation of turbulent heat transfer in jet impingement of air flow onto a flat wall," Engineering Applications of Computational Fluid Mechanics, vol. 1, no. 4, pp. 314-324, 2014.

[8] A. Abdel-Fattah, "Numerical and experimental study of turbulent impinging twin-jet flow," Experimental Thermal and Fluid Science, vol. 31, no. 8, pp. 1061-1072, 2007.

[9] S. Qiu, P. Xu, Z. Jiang, and A. S. Mujumdar, "Numerical modeling of pulsed laminar opposed impinging jets," Engineering Applications of Computational Fluid Mechanics, vol. 6, no. 2, pp. 195-202, 2012.

[10] Y. Jiang, P. Xu, A. S. Mujumdar, S. Qiu, and Z. Jiang, "A numerical study on the convective heat transfer characteristics of pulsed impingement drying," Drying Technology, vol. 30, no. 10, pp. 1056-1061, 2012.

[11] J. Taghinia, M. M. Rahman, and T. Siikonen, "Numerical investigation of twin-jet impingement with hybrid-type turbulence modeling," Applied Thermal Engineering, vol. 73, no. 1, pp. 648657, 2014.

[12] B. Weigand and S. Spring, "Multiple jet impingement-a review," Heat Transfer Research, vol. 42, no. 2, pp. 101-142, 2011.

[13] E. E. M. Olsson, L. M. Ahrné, and A. C. Trägårdh, "Flow and heat transfer from multiple slot air jets impinging on circular 
cylinders," Journal of Food Engineering, vol. 67, no. 3, pp. 273280, 2005.

[14] S. Caliskan, S. Baskaya, and T. Calisir, "Experimental and numerical investigation of geometry effects on multiple impinging air jets," International Journal of Heat and Mass Transfer, vol. 75, pp. 685-703, 2014.

[15] M. Draksler, B. Ničeno, B. Končar, and L. Cizelj, "Large eddy simulation of multiple impinging jets in hexagonal configuration-mean flow characteristics," International Journal of Heat and Fluid Flow, vol. 46, pp. 147-157, 2014.

[16] N. Kharoua, L. Khezzar, and Z. Nemouchi, "Flow structure and heat transfer in multiple impinging jets," Heat Transfer Research, vol. 47, no. 4, pp. 359-382, 2016.

[17] M. V. De Bonis and G. Ruocco, "Modelling local heat and mass transfer in food slabs due to air jet impingement," Journal of Food Engineering, vol. 78, no. 1, pp. 230-237, 2007.

[18] M. V. De Bonis and G. Ruocco, "Conjugate heat and mass transfer by jet impingement over a moist protrusion," International Journal of Heat and Mass Transfer, vol. 70, pp. 192-201, 2014.

[19] A. Yahyaee, K. Esmailpour, M. Hosseinalipour, and A. S. Mujumdar, "Simulation of drying characteristics of evaporation from a wet particle in a turbulent pulsed opposing jet contactor," Drying Technology, vol. 31, no. 16, pp. 1994-2006, 2013.

[20] G.-P. Bai, G.-C. Gong, F.-Y. Zhao, and Z.-X. Lin, "Multiple thermal and moisture removals from the moving plate opposite to the impinging slot jet," Applied Thermal Engineering, vol. 66, no. 1-2, pp. 252-265, 2014.

[21] A.-L. Ljung, T. S. Lundström, B. D. Marjavaara, and K. Tano, "Convective drying of an individual iron ore pellet-analysis with CFD," International Journal of Heat and Mass Transfer, vol. 54, no. 17-18, pp. 3882-3890, 2011.

[22] G. Lu, Y.-Y. Duan, X.-D. Wang, and D.-J. Lee, "Internal flow in evaporating droplet on heated solid surface," International Journal of Heat and Mass Transfer, vol. 54, no. 19-20, pp. 44374447, 2011.

[23] A. S. Mujumdar, "Book review: handbook of industrial drying, third edition," Drying Technology, vol. 25, no. 6, pp. 1133-1134, 2007.

[24] H. Hardisty and M. Can, "An experimental investigation into the effect of changes in the geometry of a slot nozzle on the heat transfer characteristics of an impinging air jet," Proceedings of the Institution of Mechanical Engineers, Part C: Journal of Mechanical Engineering Science, vol. 197, no. 1, pp. 7-15, 1983.

[25] D. M. Himmelblau and J. B. Riggs, Basic Principles and Calculations in Chemical Engineering, Bernard Goodwin, Upper Saddle River, NJ, USA, 2004.

[26] F. P. Incropera, D. P. Dewitt, T. L. Bergman, and A. S. Lavine, Fundamentals of Heat and Mass Transfer, John Wiley \& Sons, Hoboken, NJ, USA, 2007.

[27] ANSYS, CFX-Solver Theory Guide, ANSYS CFX Release 14, 2011. 


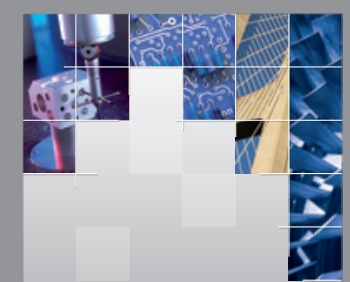

\section{Enfincering}
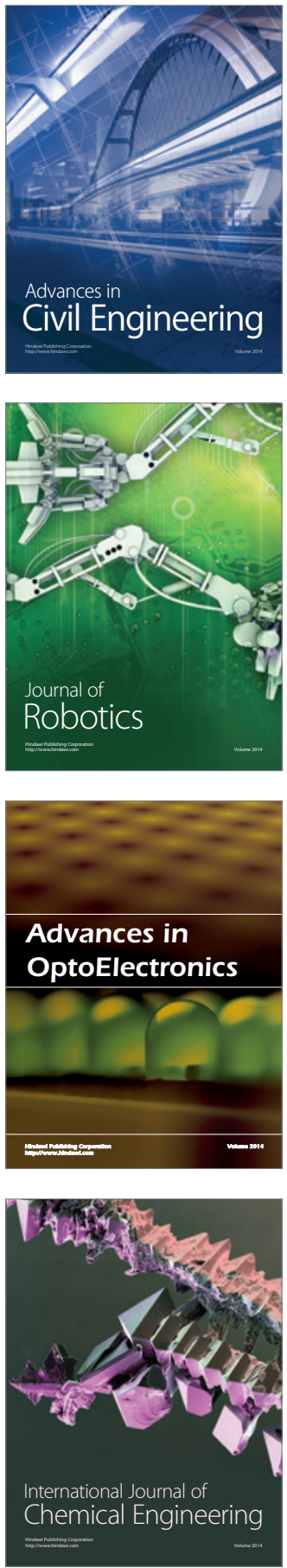

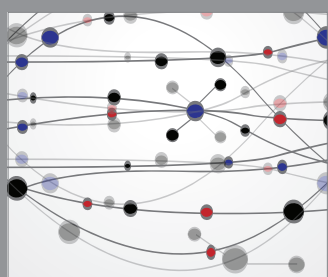

The Scientific World Journal

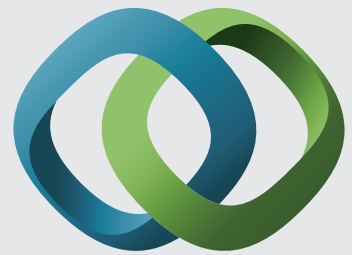

\section{Hindawi}

Submit your manuscripts at

https://www.hindawi.com
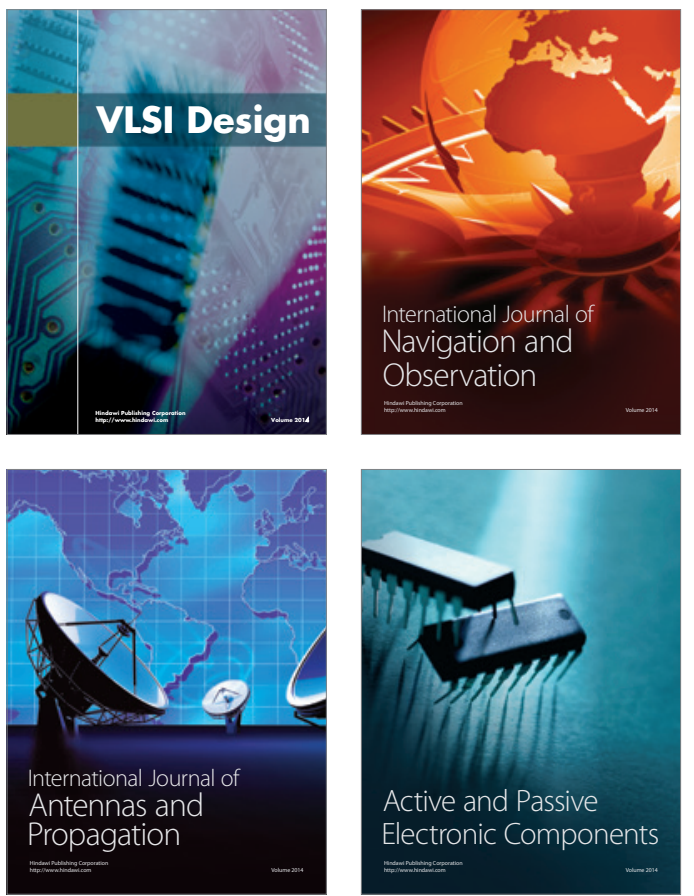
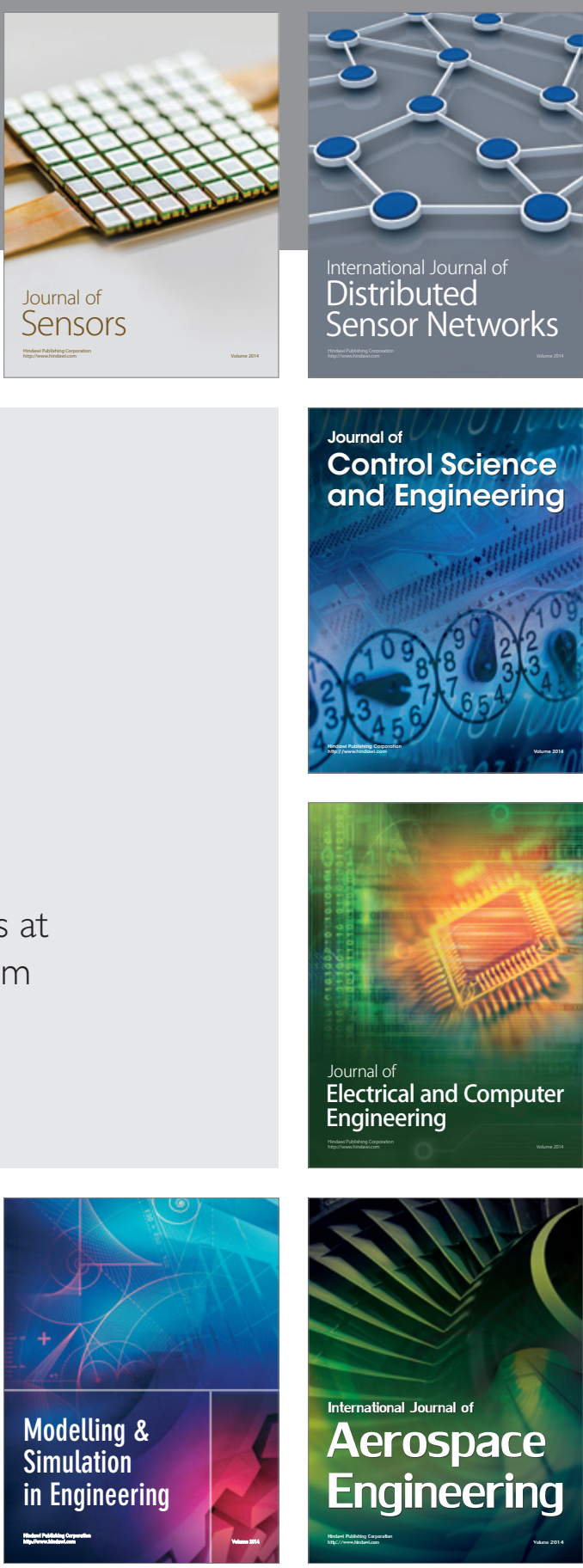

International Journal of

Distributed

Sensor Networks

$-$

Joumal of

Control Science

and Engineering
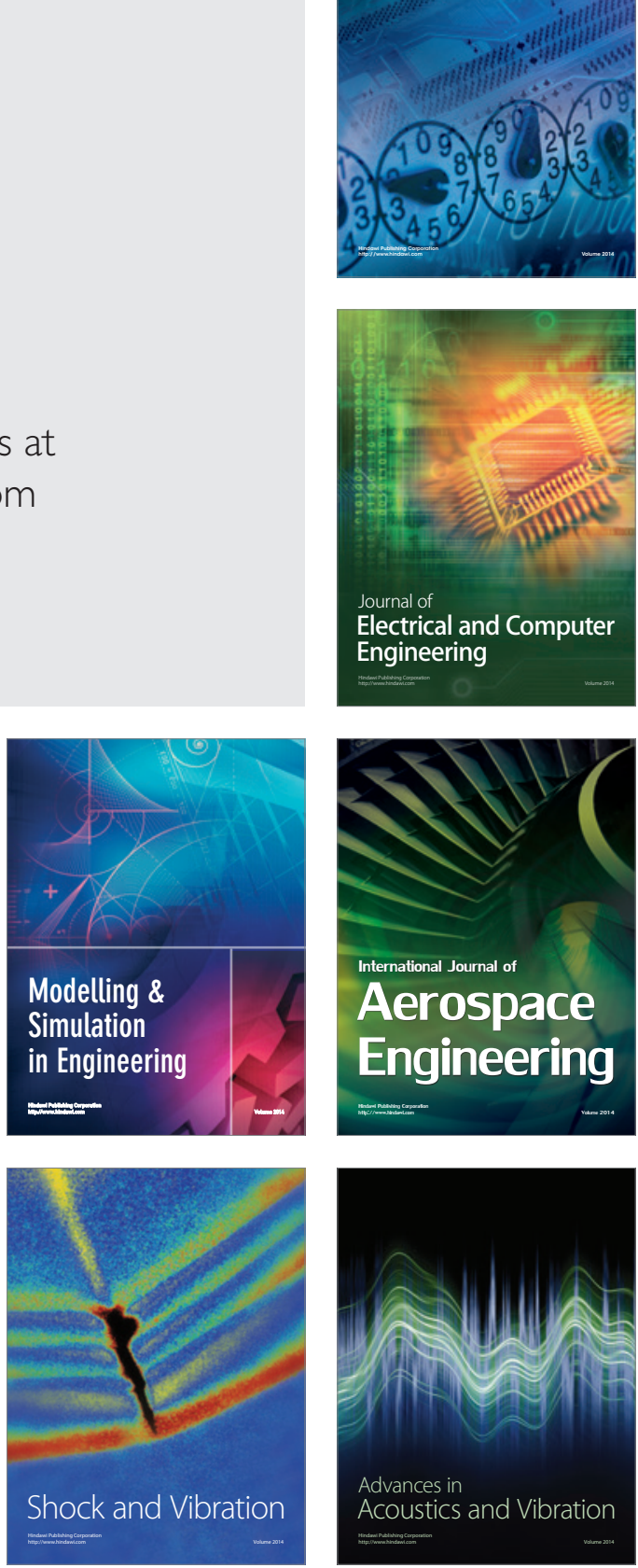